\title{
An Empirical Study on Learning-oriented Assessment
}

\author{
Yang Gao \\ Tan Kah Kee College, Xiamen University, Zhangzhou, China \\ 148253908@qq.com
}

Keywords: learning-oriented assessment, autonomy, meta-cognitive strategies.

\begin{abstract}
The paper focuses on the theoretical innovation of learning-oriented assessment (LOA) concept and investigates its rationale in practice via an empirical study. Firstly, the developed LOA is theoretically interpreted as an aid to facilitate current learning process, and autonomy for future learning and assessment. Secondly, the paper explores the effectiveness of implementing the innovative LOA in the empirical study where three research questions are raised. The data shows its success as a learning tool in practice. Lastly, some conclusions are drawn including a summary of theoretical explanations of LOA and answers to the research questions in the empirical study.
\end{abstract}

\section{Introduction}

For some Chinese tertiary students, their learning is passive or test-oriented. Summative assessment accounts for this kind of learning. In order to improve the learning, formative assessment is conducted to emphaise the move from learning product to learning process. It has been widely acknowledged as a promising alternative to facilitate learning. Carless [1] and Keppell \& Carless [2] go further, arguing the concept of learning-oriented assessment (LOA). LOA develops formative assessment and establishes three principles. It lays emphasis on learning process and reflects the synergy between summative and formative assessments. Yet, Carless' LOA can be far further promoted in combination with learner autonomy in order to address the problems of passive learning and test-oriented learning. Moreover, while there are numerous arguments of alternative assessments to aid learning, little experimental evidence gets access to determine whether and how far these arguments to be valid, especially in EFL context. Thus, with the theoretical development of alternative assessments, the call for more empirical researches concerning the rationale and effects of alternatives are increasingly strong.

This paper aims to develop and evaluate learning-oriented assessment in theory and practice. The following sections are organised as follows. Section 2 depicts the theoretical development of LOA concept, followed by an empirical study including three research questions (Section 3) and research method (Section 4). Results and discussions in the empirical study are presented in Section 5. Section 6 offers conclusions drawn according to the conceptual innovation and the discussions in the empirical study. 


\section{Literature review}

\subsection{Carless' concept of LOA}

Concept of LOA originates from Carless' researches [1][2]. He claims that LOA is a kind of effective assessment and its effectiveness, namely, learning orientation, is shown as its emphasis on firstly facilitating learning and then certifying achievement [1]. In his words [1], an assessment contains two elements including 1) certification of learning, namely, summative function, and 2) promotion of learning, namely, formative function. The overlap between the two elements is LOA [1]. In other words, LOA reflects both formative and summative functions, but the formative one is firstly important. Due to a synergy between summative and formative functions, LOA can be achieved in either of them as long as it meets its three principles including: 1) assessment activities employed as learning tasks, 2) learner engagement during assessment, like, peer- or self- assessment, making criteria and involving in quality exemplars, and 3) sustainable and productive feedback effecting present and future learning. Of the principles, the first one is most influential because deep learning is implicit in it. Surface learning, like, 'short-term bursts' or mechanical memorising is not the objective of LOA [1].

\subsection{The innovation of LOA}

Although LOA concerns the depth of learning, it is not fully explained that which one, current learning or future one, or both, should be promoted in LOA. The only clue comes from the third principle about effective feedback helping present and future learning. But it cannot fully answer the question. In order to address the problem, LOA should be further developed. The innovative LOA is shown in Figure 1.

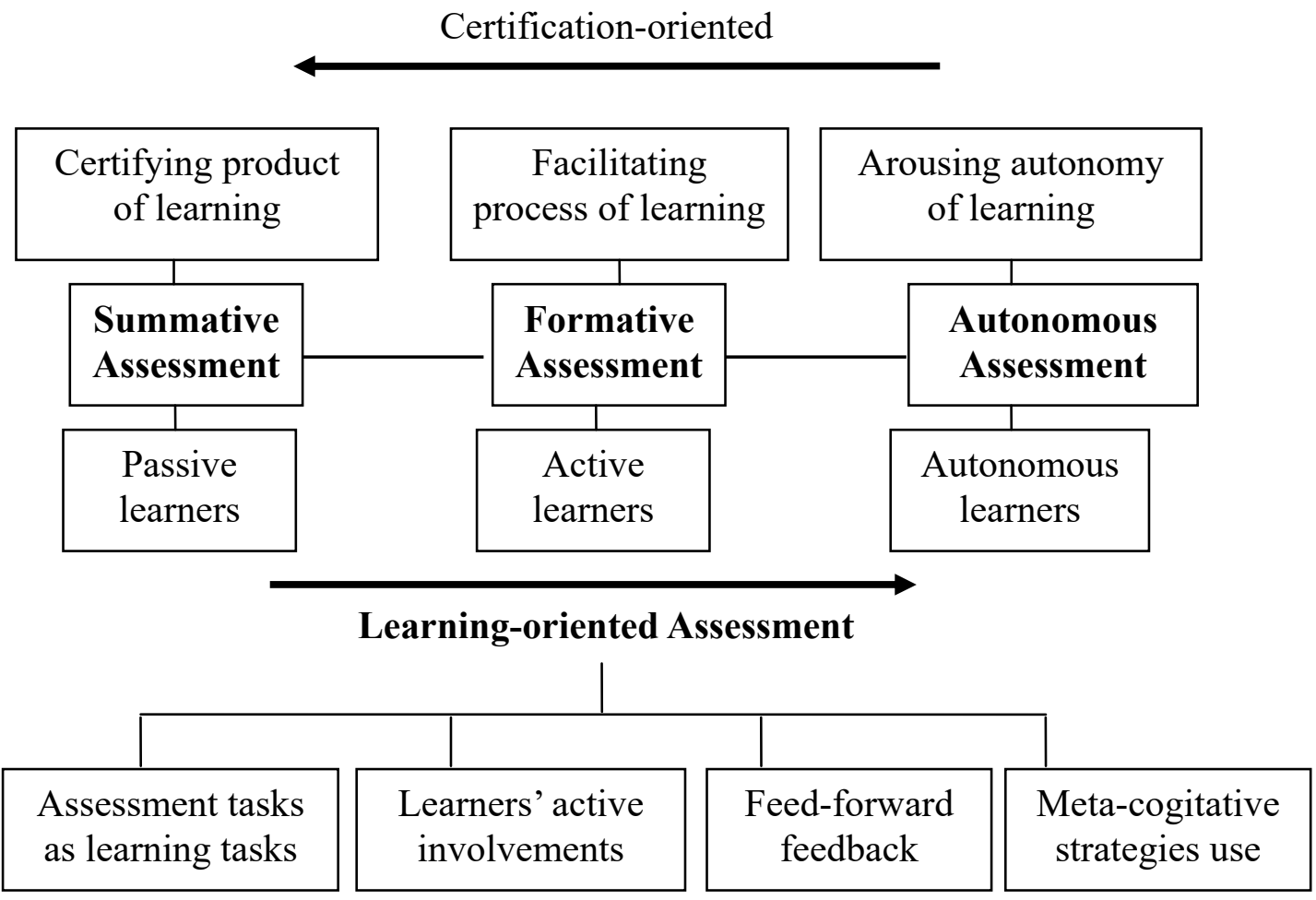

Figure 1: The Innovative LOA

Generally, the innovative LOA is able to measure learning product, to facilitate current learning, 
and also to give insight into autonomy in future learning. From the figure above, a new horizon of LOA can be characterised as following from three aspects: a new principle, components and features.

\subsection{Comparison among the innovative LOA, Carless' LOA and Mok's SDLA}

The innovative LOA is on the basis of Carless' concept of LOA [1] and is greatly inspired by Mok's work [3][4] on SDLA (self-directed learning-oriented assessment). On the one hand, the developed LOA greatly depends on Carless' concept of LOA. The three principles in Carless' LOA and the added one of 'using meta-cogitative skills', are fundamental elements in the new LOA. On the other hand, the new LOA is explored in light of the Mok's SDLA. Based on autonomous learning and LOA, SDLA integrates assessments with learning [4]. Although the aim of SDLA, namely, fostering learners' self-direction, is the same as that of the developed LOA, the distinction between them is obvious.

Firstly, the new LOA has the clear principles but no principle can be seen in SDLA. The principles are vital as the criteria to define and distinguish a specific assessment mode. In practice, instructors and students can also use the principles as guidelines to direct their beliefs and actions into route required.

Secondly, autonomous assessment in the innovative LOA is different from assessment as learning in SDLA. The concept of assessment as learning in SDLA is only equivalent to one element of autonomous assessment, that is, self-discipline, in the innovative LOA. The learners' awareness of autonomous assessment, as the other element in autonomous assessment, is absent in SDLA

Finally, the new LOA is not only seen as a mechanical combination of formative / summative / autonomous assessments but puts more emphasis on the move from summative assessment to formative assessment and then to autonomous assessment. Thus, the innovative LOA provides more chances for some assessments initial with summative function to be developed under the direction of the movement.

\section{Research questions in the empirical study}

The empirical study is conducted to evaluate the rationale of the innovative LOA in practice in EFL speaking context. Specific research questions that the study aims to address are as follows: 1) Which one, the LOA or traditional assessment, is more effective in raising learners' English speaking proficiency? 2) What are the learners' perspectives of implementing the LOA in the EFL context? 3) What are the difficulties encountered and suggestions taken during the practice?

In this study, RQ1 is addressed by the results of English speaking tests as pre-/post-tests. The participants in the study are surveyed about their responses towards RQ2. And answers to RQ3 are offered through a summary of qualitative data from teacher-learner interviews and teaching diaries.

\section{Research method}

\subsection{Background}

This empirical study practised the innovative LOA in EFL context. It is made in the course of 'English Speaking' in mainland of China over the period from March to June in 2015. The course is not required to be registered with my university. The researcher ran the course particularly for the empirical study. Thus the course did not provide any credit to the learners' university study. The course book, English language newspapers, English videos have been mainly attractive as learning materials. Besides the improvement of spoken English, the vast coverage of various topics can 
widen the learners' horizon, enrich their general knowledge in English context, and enlarge their English vocabulary [5]. The course is taught by the researcher responsible for plan, conduction and report of the research study. The university where the course is administrated has never adopted the LOA in English class.

\subsection{Participants}

The course is conducted in two classes: an experimental class and a control one. All the participants are freshmen in non-English major in my university with ages ranging from 18 to 20 years. They have learned English formally for over ten years from primary to middle school. The participants in this present study are non-randomly selected. Section covers freshmen at each scale of scores in the placement test in the university. The participants chosen are assigned to the experimental class (51) and the control one (53).

\subsection{Procedures}

Both the two classes have the same learning materials and teaching method, but different assessment ways. The course in the control class is organised in a traditional way where the teacher in control class determines learning objectives and assessment criteria of the course. And a final test is prepared for the evaluation of the course. Differently, the course in the experimental class is carried out in five steps according to the research questions.

Step 1: Preparation work. the teacher sets up learning objectives and assessment criteria for reference. Teaching plan, learning materials and the participants and are also prepared before the course.

Step 2: Pre-course training. A pre-course training programme is administrated to introduce the concept of the innovative LOA in experimental class, while there is no training programme for control class. Past researches on using alternative assessments among Asian learners [5][6] suggest that they will have the trouble of implementing the alternatives such as portfolio assessment because of inadequate experience. Thus a pre-course training is necessary to provide the learners with guidelines of using the alternatives [6].

Several open-questions are conducted at the beginning and end of the pre-course training in order to exam the participants' knowledge and experience of the LOA. The responses report that the learners have neither knowledge nor experience of the LOA before the training but have learned the basic knowledge of the LOA at the end of the training programme.

Step 3: Establishing learning objectives and assessment criteria. The teacher in the control class is a decision-maker and directly tells the learners learning objectives and assessment criteria, while the learning goals and assessment criteria are established via class discussion in the experimental class.

In an attempt to set up learning goals, the learners in the experimental class are firstly invited to write down their learning goals described in the course. Then, the learning goals suggested by the teacher are offered. As a facilitator, the teacher encourages the learners to make an independent thinking through a comparison between learners' own aims and the learning goals offered by the teacher. After that, the whole class discusses and establishes the learning objectives of the course. The objectives comprise of 1) developing the learners' abilities to speak at length for a topic; 2) promoting English speaking competence including linguistic competence and strategic competence; 3) expanding world views.

In terms of assessment criteria, the teacher in the experimental class facilitates the establishment of assessment criteria. The learners are asked to write down their perspectives of assessment standards, followed by a whole class discussion. During the discussion, the teacher guides them to move their concerns from learning product to learning process. After the discussion, the criteria are 
identified as four assignments in Table 1. Of the assignments, the peer-/self- assessments of speaking performance in Assignment 3 are based on Liu and Wang's research [7] on assessment criteria of EFL speaking for Chinese learners. They set up assessment criteria of spoken English for Chinese learners among EFL context via an empirical research. And the teacher introduces and explains each assessment criterion in details for their comprehensive understanding of assessment criteria in the course.

Table 1 The criteria are identified as four assignments

\begin{tabular}{|l|l|l|}
\hline & Perception & Content \\
\hline Assignment 1 & $15 \%$ & A written summary on how to develop longer oral response \\
\hline Assignment 2 & $40 \%$ & Peer- and self-assessment of speaking performance \\
\hline Assignment 3 & $25 \%$ & Reflective journals of learning for each week \\
\hline Assignment 4 & $20 \%$ & Exam: answering questions \\
\hline
\end{tabular}

Step 4: Course study. During the course study, the teacher organises and monitors the learning as the course proceeds. In week 1, the teacher helps the learners identify the learning objectives and assessment criteria via class discussion. Following two weeks are concerns with developing the learners' abilities to speak at length. Week 4 sees an activity of brain storming organised in order to make the learners' views on a topic in diversity. In weeks 5 and 6 , the learners are required to read three long oral scripts. They should analyse and discuss the structure of the scripts with others. Then, the teacher would facilitate them to find out three basic patterns of developing long speech including 1) problems - causes - effects - solutions - related problems; 2) who, what, where, when and why; and 3) opinions - reasons - pros - cons. After that, the learners are required to write down a summary as Assignment 1 about how to organise information for a long speech with specific examples. During weeks 7 and 8, the activity of retelling stories and one-minute speaking are organised to develop grammatical knowledge and textual knowledge of spoken English including cohesion and organisation. From weeks 9 to 12, the learners discuss several hot topics in order to increase their functional knowledge of illocutionary competence and sociolinguistic knowledge. And the hot topic discussions also emphasise a review of the related knowledge learned before. The learners work in groups of three. During group work, they interact with each and make long presentations of one topic. Their presentations are recorded for peer-assessment and self-assessment. The teacher helps identity their strengths and weaknesses of speaking, and effectiveness of peer-assessment and self-assessment. Productive feedback is offered during the tasks or activities. Besides, the teacher-assessment of individual speaking is made for the comparison with peer-/self-assessment. The similarities and differences among peer-/self-/teacher-assessment are analysed with the teacher's feedback to foster their autonomy. The learners in Week 12 should present their individual peer assessment and self-assessment for a selected hot topic as Assignment 2. The weeks 13-15 experience the three learning tasks including public speaking, role playing and debating in order to enhance the speaking strategies of goal setting, appraising and planning. Finally, the learners attended an exam last week.

Step 5: Learning evaluation. Unlike traditional tests in control class, the learning evaluation in the experimental class is learning-oriented. The evaluation contains four assessments (see Table 1). Assignment 1 is about a written summary in Week 4 which reflects the understanding of developing a speech at length. In week 12, the teacher assesses Assignment 2 including the learners' speaking performance $(20 \%)$, and the efficiency of their self-assessment $(10 \%)$ and peer-assessment $(10 \%)$. Besides, the learners are required to write a weekly reflective journal where a summary of learning and critical thinking of their learning are included. The teacher's feedbacks for reflective journal are also weekly provided in order to monitor their learning process. The evaluation of their reflective journals focuses on whether their reflective words reflect deeper learning, and spur their responses 
to the teacher's feedbacks. Assignment 4 in final week is different from traditional final test. It only takes up $20 \%$ of total grades. The learners are given 7 key questions about the course (see Appendix 1) two weeks before. And they only need to select four of them to answer during the exam.

\subsection{Instruments}

In order to realise methodological triangulation [8], both quantitative and qualitative methods are employed in this experimental study. The data collected comes from tests, questionnaires, interviews and teacher's diaries.

Quantitative data contains the participants' proficiency tests and questionnaire survey. The participants' oral English proficiency in both experimental and control classes is assessed via a pre-test and a post-test. T-tests of the data in pre-/post-tests analysed by SPSS 13.0 ascertains the differences in the learners' oral proficiency at pre- and post-course. The post-course questionnaire, translated in Chinese, comprises of both five Likert-scaled questions ranged from 5 'strongly agree' through 3 'not sure' to 1'strongly disagree'. The questionnaire is designed to elicit the learners' views on the LOA. The design of the questionnaire items is firstly based on the theoretical explanations of the innovative LOA. It is also supported by past researches concerning impact of alternative assessments on EFL oral-listening learning in China [9][10][11] and on the factorial analysis of autonomous language learning among Chinese learners [12][13[14]]. The questionnaire items containing a series of statements aim to investigate the implementation of the LOA in six areas: a) general questions; b) self-awareness and learners' ownership; c) using meta-cognitive strategies; d) current learning and future learning; e) learners' involvements; and f) teacher's feedback. All the learners return their questionnaires. Chi square test is conducted via SPSS 13.0 to analyse their replies to the questionnaire.

Qualitative data in this probe comes from learners' interviews and the teacher's diaries. The diaries record the teacher's observations throughout the empirical study, the learners' verbal or non-verbal responses, the difficulties encountered, and the teacher's reflective responses. The information from qualitative data is catagorised and analysed as direct evidences of arguments as well as complementary explanations of quantitative data.

\section{Results and discussion}

This section demonstrates the results of the quantitative and qualitative data analysis and the relevant analysis.

\subsection{About data of oral English pre-tests in the experimental and control classes}

In order to compare the learners' grades in English oral test in the experimental and control groups at the beginning of the course, an independent-sample t-test including Levene's test and t-test for equality of means is administrated. The data is shown in Table 2 and 3.

The data of Table 2 indicates the equal Variances between the two groups $(p=.085>.01)$. Thus, the t-test for equality of means should be conducted based on the equal Variances assumed (in Table 3). As can be seen from Table 3 , there is no statistically significant difference $(\mathrm{t}=-.561, \mathrm{df}=102, \mathrm{p}$ $=.576>.01)$ between the experimental class $(\mathrm{M}=72.618, \mathrm{SD}=10.595)$ and the control $(\mathrm{M}=$ $73.959, \mathrm{SD}=13.524)$ one with respect to their spoken proficiency, which certifies the homogeneity of the learners' oral English level in both classes before the study begins. 
Table 2: Results of Levene's Test for Equality of Variances in Oral Pretest

\begin{tabular}{|l|l|l|}
\hline Equality of Variances & F & Sig. \\
\hline Difference between Exp. \& Cont. & 3.035 & $.085^{*}$ \\
\hline \multicolumn{2}{|r}{ *Alpha level= .01 }
\end{tabular}

Table 3: Results of T-test for Equality of Means in Oral Pretest

\begin{tabular}{|l|l|l|l|l|l|l|l|}
\hline & Mean & $\mathrm{N}$ & $\mathrm{SD}$ & Std Error Mean & $\mathrm{t}$ & $\mathrm{df}$ & Sig. (2-tailed) \\
\hline Exp. class & 72.618 & 51 & 10.595 & 1.484 & & & \\
\hline Cont. class & 73.959 & 53 & 13.524 & 1.858 & & & \\
\hline Class difference & -1.341 & \multicolumn{7}{|c|}{-2.929} & & -.561 & 102 & $.576^{*}$ \\
\hline
\end{tabular}

\subsection{About data of oral English post-tests in the experimental and control classes}

As described in the instruments (in Section 4.4), the learners in the experimental and control classes attend post-test of English oral proficiency at the end of the ocurse. To compare their scores in the tests, the researcher employs an independent-sample t-test containing Levene's test and t-test for equality of means (see Tables 4 and 5).

Table 4: Results of Levene's Test for Equality of Variances in Oral Post-test

\begin{tabular}{|l|l|l|}
\hline Equality of Variances & F & Sig. \\
\hline Difference between Exp. \& Cont. & 9.635 & $.002^{*}$ \\
\hline
\end{tabular}

Alpha level $=.05$

Table 5: Results of T-test for Equality of Means in Oral Post-test

\begin{tabular}{|l|l|l|l|l|l|l|l|}
\hline & Mean & $\mathrm{N}$ & SD & Std Error Mean & $\mathrm{t}$ & $\mathrm{df}$ & Sig. (2-tailed) \\
\hline Exp. class & 84.839 & 51 & 11.746 & 1.645 & & & \\
\hline Cont. class & 78.371 & 53 & 16.236 & 2.230 & & & \\
\hline Class difference & 6.488 & & 4.480 & & 2.334 & 102 & $.022^{*}$ \\
\hline
\end{tabular}

As the results of Table 4, a significant difference of Variances between the two groups is shown $(p=.002<.05)$. Thus, the following t-test for equality of means should be calculated according to the unequal Variances assumed. The number in Table 5 shows a significant difference $(\mathrm{t}=2.334 \mathrm{df}$ $=102, \mathrm{p}=.022<.05)$ between the experimental class $(\mathrm{M}=84.839, \mathrm{SD}=11.746)$ and the control one $(\mathrm{M}=78.371, \mathrm{SD}=16.236)$ class with regard to their oral proficiency. The data confirms that the learners in the experimental class have gained much greater progress in English speaking than those in the control group. Furthermore, the standard variation in the experimental group is obviously less than that in the control one, which reveals that the LOA closes the gap among individual differences in the experimental class.

\subsection{About data of oral English pre-test and post-test in the experimental class}

The results of the learners' pretest and post-test on English speaking in the experimental class are 
summarised in Table 6. The table represents that the results of post-test of English speaking for the participants in the experimental class are significantly different from their pretest ones $(\mathrm{t}=-7.186$, $\mathrm{df}=50, \mathrm{p}=.000<.05)$. The results argue that due to the innovative LOA in course study, the learners in the experimental one have made a great improvement in English speaking.

Table 6: Results of Paired-Samples Test for Oral tests in Experimental Class

\begin{tabular}{|l|l|l|l|l|l|l|l|}
\hline & Mean & $\mathrm{N}$ & SD & Std Error Mean & $\mathrm{t}$ & $\mathrm{df}$ & Sig. (2-tailed) \\
\hline Pair & & & & & & & \\
\hline Pre-test & 72.618 & 51 & 10.595 & 1.484 & & & \\
\hline Post-test & 84.839 & 51 & 11.746 & 1.645 & & & \\
\hline Paired difference & -12.221 & & & & -7.186 & 50 & $.000 *$ \\
\hline
\end{tabular}

\subsection{About data of oral English pre-test and post-test in control class}

Table 7 indicates the information of the learners' pretest and post-test of spoken English in the control class. The paired sample t-test in Table 7 reveals that the results of post-test of speaking for the learners in the experimental class demonstrates significant difference from their pretest results $(\mathrm{t}=-2.410, \mathrm{df}=52, \mathrm{p}=.020<.05)$. It can be found the results that the learners' oral proficiency has been promoted through the course study.

Table 7: Results of Paired-Samples Test for Oral tests in Control Class

\begin{tabular}{|l|l|l|l|l|l|l|l|}
\hline & Mean & N & SD & Std Error Mean & t & df & Sig. (2-tailed) \\
\hline Pair & & & & & & & \\
\hline Pre-test & 73.958 & 53 & 13.524 & 1.858 & & & \\
\hline Post-test & 78.371 & 53 & 16.236 & 2.230 & & & \\
\hline Paired difference & -4.413 & & \multicolumn{7}{|c|}{$*$ Alpha level $=.05$} & -2.410 & 52 & $.020 *$ \\
\hline
\end{tabular}

\subsection{About qualitative data from interviews and teaching diaries}

The individually face-to-face interviews at the end of the course are conducted. The interviews welcome any questions from the learners and attempt to realise the pros and cons of the LOA. The learners are encouraged to comment their learning with the LOA. Moreover, the teaching diaries have weekly recorded the challenges or reflections of learning, instructions and assessment through classroom observations. Some significant points should be highlighted from the interviews and teaching diaries.

During the interviews, most learners not only identify the positive effects of the LOA for current learning and learner autonomy for future, but also support its benefits of affective adjustment. They argue that the LOA boosts their self-esteem and confidence, increases learning motivation and desire, makes them relaxed when they are nervous or anxious. They say that they enjoy the process of learning.

Moreover, a majority of the learners in the interviews highlight that the LOA cultivates their habits of reflection and gains how to write a reflective journal. The teaching diaries also record their change from ineffective reflection into productive reflection. During the first two weeks, most learners fail to write down an effectively reflective journal. Most only describe some details of their class performance. A few record learning notes in the classroom study, some write down simple 
words of parsing the teacher. Others even write down their feeling of university life unrelated to course study. Analysing these journals, the teacher found out that the lack of the teacher' guides accounts for the failure of writing reflective journals. Then, the teacher presents a sample of reflective journal to the whole class. The reflective journals contain a summary of learning strengths and weaknesses and the related critical thinking. Besides, the teacher's feedbacks also demand more evaluative words rather than descriptive ones in reflective journals. Although critical thinking is not easy to the learners due to the Asian culture where classroom is teacher-centered, the sustained guides and encouragement and demands of independent and creative thinking gradually cultivate their competence of critical thinking. At the end of the course, their reflective journals contain not only the analysis of learning weaknesses, but also the self-discipline of critical thinking, the further consideration of a topic which has been discussed in class, the doubts of the teacher's suggestions, the inquire of future speaking learning, and the reflections of the course design. Thus, the reflective journals play the role of linking formative assessment to autonomous assessment through the cultivation of critical and independent thinking.

Besides the pros of the LOA, some cons are also identified from qualitative data. According to the teaching diaries, the greatest challenge for the teacher in the course is the enormous workload including giving feedback to weekly reflective journal and analysing the difference among the teacher's assessment, the learners' peer assessment and their self-assessment. The learners' words in the interviews also reveal that the LOA have increased their burdens of learning. They claim that they take a lot of time in the LOA. Lo encounters similar problems and suggests the decrease of teaching content and the increases of peer assessment to reduce the teacher's burden [5]. The suggestion is not satisfactory because they will influence the quality of learning and assessment. The development of learner autonomy in learning and assessment, the increasing emphasis of moving from formative assessment to autonomous assessment, and the advance of educational technology are called for as the long-term solutions.

In addition, it is also found from the interviews that although the LOA enables the learners to be concerned with learning process where their merits and shortcomings are identified, improving the limitations is ineffective. The duplicated records of similar mistakes or shortcomings of learning in their weekly reflective journals support the point. It can be explained by several reasons. Firstly, the teacher's feedbacks may be insufficient in handling their weaknesses. Secondly, the improvement of language proficiency is a slow process. Thirdly, the LOA may make some learners lazier and more reliable to the teacher. Finally, the overwork in the LOA may make some learners frustrated and fulfill the reflection work perfunctorily.

\section{Conclusions}

This article provides insights into using LOA to facilitate both current and future learning according to the relevant theoretical explanation and empirical verification via the case study. Based on the theoretical development, the case study is directed by the three research questions. Several findings in this article are summarised by the determinative explanations of innovative LOA and conclusive answers to the research questions

In theory, Carless' concept of LOA can be developed by the emphasis of autonomy in future learning and assessment. Besides it, for future research, Carless' LOA provides multi-dimensional perspectives on assessment. The pattern of 'something-oriented assessment' gives us an insight into a new horizon for assessment. Assessment cannot only be discussed in a two-dimensional space where there are only formative and summative functions. More factors such as praise or pressure can be added into future discussion. Then many new types of assessment can be produced, like, praise-oriented assessment [7], motivation-oriented assessment, and pressure-oriented assessment. 
Therefore, the future research on assessment can be encouraged in a multi-dimensional space.

In practice, conclusive answers to the three research questions (in Section 3) can be drawn by the support of quantitative and qualitative data analysis.

For Research Question 1, no significant difference between the pre-tests in the experimental and control classes demonstrates the same level of the spoken English proficiency of the learners in the two classes at the beginning of the course. After the course, the greater progress of oral proficiency made by the learners in the experimental class is seen from the comparison between the post-tests in the two classes, which illustrates that the LOA is more effective than traditional assessment to develop oral English proficiency.

In terms of Research Question 2, most learners' views support the rationale and value of the innovative LOA in EFL context. According to their views, the LOA is a learning tool to develop the autonomous assessment including self-awareness and self-discipline of using meta-cognitive strategies. It focuses on current learning process and future learning, and demands effective teacher's feedback and learner involvement. Besides, the learners' responses for Research Question 2 show that the LOA is regarded as an orientation moving from learning product to learning process to future learning, a synergy among summative, formative and autonomous assessment, a link between current learning and future one, and an interaction among learning, instruction and assessment.

In the senses of Research Question 3, the main problems encountered during the practice contain 1) unsatisfactory time management of learning; 2) monitoring is not used as successfully as other meta-cognitive strategies; 3) greatly increasing workload for both the teacher and the learners; 4) relevantly long period of handling learning weaknesses; 5) the initiative failure of writing reflective journals in the first two weeks. Based on the analysis of the reasons of these challenges, some recommendations can be taken to address the problems. Firstly, teacher's guides and peer learning are beneficial to improve time management and writing reflective journals. Secondly, the emphasis of learner autonomy and the development of technology for education can reduce the enormous workloads. Thirdly, encouragement and monitoring in teacher's feedback can develop full use of meta-cognitive strategies. Lastly, the increase of language proficiency requires relevant long time but peer learning and teacher's feedback can cultivate the learners' persistence.

Eventually, although the empirical research successfully supports the theoretical development of LOA, it still has its limitations. Firstly, the empirical verification is only conducted in EFL context. Secondly, the length of research is limited. In order to cope with the shortcomings, further researches on LOA should cover more contexts and require longer period of study.

\section{References}

[1] Carless, David (2007) Learning-oriented assessment: conceptual bases and practical implications, Innovations in Education and Teaching International, 44(1), 57-66.

[2] Keppell, Mike \&Carless, David (2006) Learning-oriented assessment: a technology-based case study, Assessment in Education, 13(2), 179-191.

[3] Mok, M.M.C. (2012) Assessment reform in light of self-directed learning oriented assessment framework: theoretical basis (Chinese version: Li Yong Zi Zhu Xue Xi Dong Xiang Ping Gu Kuang Jia Bian Ge Ping Jia: Li Lun Ji Chu), Examinations Research, 4 (33), 79-89.

[4] Mok, M.M.C. (2013). The theory and practice of self - directed learning oriented assessment. In: Mok, MMC (Ed.) Self-directed learning oriented assessments in the Asia-Pacific (Springer: Springer Science+Business Media Dordrecht), 3-22.

[5] Lo, Yafen (2010) Implementing reflective portfolios for promoting autonomous learning among EFL college students in Taiwan, Language Teaching Research, 14(1), 77-95. 
[6] Yang, Nae-dong (2003) Integrating portfolios into learning strategy-based instruction for EFL college students, International Review of Applied Linguistics in Language Teaching, 41, 293-317.

[7] Liu, Qin \& Wang, Li (2010) The feasibility of applying portfolio assessment in oral English courses for Chinese tertiary learners (Chinese version: Zhong Guo Da Xue Sheng Kou Yu Neng Li Dang An Dai Ping Jia Ke Xing Xing Yan Jiu), Foreign Language and Their Teaching, 6, 42-55.

[8] Chen, Y. (2006) EFL instruction and assessment with portfolios: A case study in Taiwan, Asian EFL Journal, 8(1) : 69-96. (Online: http://asian-efl-journal.com/March06_ymc.pdf, pp1-36)

[9] Zhu, Yanhua (2010) The application of formative assessment in teaching and testing of vocational English listening and speaking, Journal of Yunnan Agricultural University, 4(3),93-97.

[10] Chen, Jin (2009) Application of formative assessment in EFL oral-listening course in middle school (Chinese version: Fei Ce Shi Xing Ping Jia Zai Zhong Xue Ying Yu Ting Shuo Jiao Xue Zhong De Ying Yong), Journal of Basic English Education, 11(4), 74-79

[11] Meng, Fanshao (2008) A study of application of self-assessment in instruction of English listening and speaking, Journal of Ningbo University (Educational Science Edition), 30(4), 118-120.

[12] Su, Fengyan \& Wu, Kongyun (2008) Factorial analysis of the components of autonomous English listening learning' (Chinese version: Ying Yu Ting Li Zi Zhu Xue Xi Neng Li Gou Cheng De Ying Zi Fen Xi), Journal of Xi'an International Studies University, 16(4), 69-71.

[13] Shen, H. (2010) The experimental study of the effect of formative assessment on autonomous learning (Chinese version: Xing Cheng Xing Ping Gu Zai Xue Sheng Zi Zhu Xue Xi Neng Li Ping Jia Zhong Zuo De Shi Zheng Yan Jiu), Journal of Tianjin Foreign Studies University, 17(2), 71-76

[14] Lu, Qiao-er \& Li, Li (2012) An empirical study of formative assessment in college English autonomous learning, Journal of Ningbo University (Educational Science Edition), 34(5), 109-111.

Appendix: Questions in the exam

1. Please give an example of organising information for a long speech?

2. How to write a reflective journal?

3. Please explain the grammatical knowledge of English speaking?

4. Please explain the textual knowledge of English speaking?

5. Please explain the pragmatic knowledge of English speaking?

6. Please explain the strategic competence of English speaking?

7. Please write down an example showing that you have expanded world views? 